DOI: 10.2478/ausfm-2021-0006

\title{
Images in Suspension: Tableaux Vivants, Gesturality and Simulacra in Raul Ruiz's film The Hypothesis of the Stolen Painting
}

\author{
Ioannis Paraskevopoulos \\ Independent researcher (Athens, Greece) \\ E-mail: ioannisparas@yahoo.co.uk
}

\begin{abstract}
The article discusses Raul Ruiz's film The Hypothesis of the Stolen Painting (1978). In the closed space of the house a parallel world emerges, where the filmic hypertext is constituted by a series of mise-en-abyme images that explore the multiple universe of tableaux vivants. The article analyses Ruiz's appropriation of Pierre Klossowski's concept of simulacra. The structure of The Hypothesis of the Stolen Painting is based upon the infinite reproduction of meaning since each simulacrum-tableau vivant leads to another. The author explores the gesturality of the bodies and its relevance to the use of language and sound in the film. Furthermore, he argues that Ruiz orchestrates the placement of the tableaux vivants in the filmic space in order to reveal the thought of eternal return.
\end{abstract}

Keywords: tableaux vivants, simulacrum, gesture, Pierre Klossowski, vicious circle.

\section{Introduction: In the House of Mirrors}

The film The Hypothesis of the Stolen Painting (L'Hypothèse du tableau volé, 1978) - along with Pierre Zucca's film Roberte (1979) - introduces Pierre Klossowski's work into cinema. The film summarizes to a large extent the main themes of the philosopher's work. Furthermore, it combines his key philosophical concepts with a close study upon Klossowski's uses of the tableaux vivants. The film can be characterized as an intellectual detective mystery story. A Collector has gathered six paintings by the 19th-century painter Frédéric Tonnerre that caused a scandal at the time and consequently have been confiscated by the police. His main preoccupation is to discover what has happened to the seventh painting. The main character is aided by a bodiless voice, that of the Narrator, which appears and disappears during the narration. Although we are not provided with further information on 
that voice, I argue that it is a reference to Klossowski's theological themes; a spirit or a demon that frequently appears in the author's novels. The Collector presents his investigatory method orally, through a series of syllogisms that interact with the recreation of the paintings in the form of tableaux vivants in the physical space of the film. The investigation leads to the revelation of the scandal: the practice of an occult ceremony by a secret society.

The film, which combines several cinematic genres such as the documentary and the essay film, could be considered as a cinematic monograph on Pierre Klossowski by Raul Ruiz. The filmmaker applies what he has called the "combinatory logic" (Ruiz 2005, 113) in constructing a film of Klossowskian occurrences. Ruiz combines multiple themes that act as substrata to the film's structure, which has multiple layers. Ruiz produces a spiral of images inside images. Having as a starting point the representations of Klossowskian themes in paintings, we come across a series of tableaux vivants and a roman-à-clef, which in turn is being reconstructed into a tableau vivant. This filmic construction is based upon the personal mythology of Pierre Klossowski, as seen in his works: Diana and Actaeon, The Crusaders, The Immortal Adolescent, the demon Baphomet. Ruiz explicitly manipulates those themes in order to construct an original story.

In adapting Klosswoski's theoretical work as well as his personal mythology, Ruiz performs a highly experimental work which can be related to Thomas Elsaesser's continuation of the thought of Gilles Deleuze. Elsaesser claims that Deleuze has managed to claim for the image "a new kind of materiality, an existence in time beyond the ephemeral and the moment, as well as investing it with energy, with agency and intensities, in short, with something akin to a life-form of its own" $(2018,5)$. Elsaesser concludes that this new type of image and the consequent conceptualization of cinema escapes the preconceived notion that cinema reflects and presents aspects of the world that we live in. He, rather, claims that cinema has become a world on its own $(2018,5-6)$. Now, the spectator does not have access to a glimpse of an imaginary reality of the world that we live in, but she/he is taking part in a process of a world-in-the-making. According to Deleuze and Elsaesser, cinema has the capacity to create a world on its own, to be a world on its own. Hence, my point of departure is that The Hypothesis of the Stolen Painting is a world that opens up to us and invites us to explore it.

Firstly, I am presenting several aspects of Klossowski's work that concern the film directly. By pointing out the details of Klossowski's personal mythology and philosophical thought, I attempt to clarify Ruiz's narration. Secondly, I am focusing on the use of sound, and more precisely of voice, in the film. The voice's role affects 
the relation to the multiplicity of images that coexist in the film and creates one more layer (a sonic layer) in the narrative. Thirdly, I am conducting a micro-historical analysis of the concept of the tableau vivant in order to point out its functions and demonstrate how it is being used in the film's narrative structure. Lastly, I am using several scenes and details in order to demonstrate the apparent coexistence of different kinds of works: the philosophical and pictorial work of Pierre Klossowski and the film of Raul Ruiz.

\section{The Work of Pierre Klossowski}

The themes that Pierre Klossowski uses and that consequently appear in the film form a vital part of the philosopher's/painter's personal mythology. Klossowski could be characterized as a modernist and a post-modernist artist at the same time. He builds a personal mythology in which he combines a mélange of historical and literary figures that he appropriates. Jacques Henric argues that Klossowski's pictorial construction "reestablishes the link between the immense territory of the pregrammatical: the mechanisms of memory, dreams, facts and gestures take place in the limits of the human or in the pre-human. The image has a transhistorical and transnational value. It dives into a past which is more distant than that of the language. It captures the infinite and the timeless" (Henric 1989, 20). In this mixture of history, theology and literature in Klossowski's personal universe, Greek mythology (as is the case of Diana) coexists with Western historical figures (as the Crusaders). Alyce Mahon notes that "the painterly and fictional spaces Klossowski invites the spectator into are thus quintessentially modern while his erotic theatrics might be viewed as post-modern before their time in insisting that the gaze is not fixed but open to play. Klossowski's eroticism is indebted to a long history of both religious and libertine texts, from the writings of Saint Augustin to those of the Marquis de Sade. Both traditions share a fascination with dualism, and it is this fascination which fuels Klossowski’s libidinous play” (Mahon 2006, 33).

Deleuze calls this unity of theology and pornography a "superior pornology" (Deleuze 1990, 282) and underlines the fact that the one reflects upon the other (Deleuze 1990, 282). It is an accomplished junction that creates the paradoxical coexistence of antithetical identities. It reunites in an extreme way various forms of thought and creates a play between their dynamic potentials. This synthesis is made explicit and is being visualized through an ambiguity of the bodies. 


\section{The Game of Images}

The Hypothesis of the Stolen Painting does not have an actual plot. Its story is concentrated entirely on the fabrication of images inside images. Firstly, the images inside the images are representations of paintings that have been reproduced in the form of the tableaux vivants. Secondly, the Collector reproduces the paintings in order to unravel the mystery that surrounds a stolen painting and its scandalous reputation in the 19th century. The key to the unraveling of the mystery is the deciphering of the gestures of the tableaux. The falsifying element in this narration is that the painter Frédéric Tonnerre, who supposedly painted the paintings, never existed. It is a figure that belongs entirely to Klossowski's modern mythology. The pseudo-painter appears several times in Klossowski's novels and Klossowski has even written an article analysing one of his works that is called Judith. One could argue that Tonnerre, apart from being a figure of reference to Klossowski's work, is at the same time his alter ego. According to Klossowski, his style is characterized by a certain realism mixed up with reverie and Neoclassicist reflections (Klossowski 2001, 120). The Collector reproduces the paintings in order to discover what occurred in the past, in order to find out the cause of the great scandal. We come across a pseudo-enactment of the past since that past never existed. The scandalous past that the Collector attributes to the paintings never existed as both the paintings and the painter are entirely fictitious. The whole film is therefore a parody of a mystery, a game of images.

Ruiz covers the cinematic space of this mystery story with many layers of fictitious creations, such as the Collector's syllogisms as well as the multiplicity of images that coexist in the mise-en-scène. The paradoxical aspect of the film lies in its use of images that contradict speech and vice versa. The Collector's speech instead of clarifying the mystery of the images creates more suspense and mystery. Furthermore, Ruiz adapts the concept of the eternal return as it has been reformulated and interpreted by Pierre Klossowski. The eternal return expresses a virtual moment in time and presents itself as a singular event. In its core, the thought of the return is non-communicable and non-exchangeable. Such a virtual moment is taking place at the end of the film. Moreover, the whole film is constructed around this idea. The world of the film reflects a fabricated arbitrariness. This unpredictable composition is formed by two different languages (i.e. the Collector's speech and the language of the bodies) that are connected to each other and that function in opposition to one another. 


\section{Filming the Mystery House. Huis Clos and the Multiplicity of Spaces}

The diegesis of the film is entirely concentrated on the space of the house. The narration takes place inside its confined limits except for the opening shot of a cul-de-sac of a Parisian road. The 19th-century bourgeois house is an additional character to the narration in the sense that the parts of the house such as the living room, the corridors, the rooms and the garden contribute both to the masking and to the unraveling of the mystery that surrounds Tonnerre's paintings. The set is a demonstration of Ruiz's theory of the "corpus of visual opinions." "Visual opinions are the automatic sequences of images touched off by the first arbitrary image created on the basis of the abstract stimulus." (Ruiz 2005, 60.) An example of "visual opinion" is presented by the filmmaker in this way: "when we go into an unknown house, we see the living room, and on that basis, along with our impressions of the external aspect of the house, we develop an opinion about the rest" (Ruiz, 2005, 60). Such an example of "unknown house" appears in The Hypothesis of the Stolen Painting. The house is presented as being a world of its own. The viewer has the impression of entering a world of mystery. The filmmaker uses a highly realistic point of view of the way in which he presents the facts and the events. Thus, the film has the appearance of being a documentary film. Furthermore, Ruiz gives a strong realistic background to the spaces that he uses. He makes us believe that these spaces do indeed hide something; they contain a mystery story whose origin and meaning we have to discover.

The impression of confinement that the house creates for the viewer produces the idea of a space which is induced with a multiplicity of possibilities. The "personality" of the house follows in many respects the gothic-story house. The large spaces, the long corridors, the doors that open and close on their own are elements that belong to the literature of the late 18th century. [Fig. 1.] Apart from the explicit reference to the symbolism of the gothic house, the black and white cinematography contributes to the mystery that surrounds both the house and the narration. [Fig. 2.] The absence of colour produces the idea of mystery in the film. We can argue that the paintings are decolourized in order to focus on their meaning. This becomes evident through the Collector's spatial movement. He conducts his investigation according to the settings of the tableaux vivants that are organized systematically in the spaces of the house.

The above reflections on the elements of the spatial organization of the film correspond to the characteristics of the huis clos film in which stories depict 
characters in an enclosed space, a genre that incorporates features of the theatrical aesthetics of space. The genre has been developed extensively in the 1970s and has formed a cinematographic language of its own. Primary examples of this language are the works of Marguerite Duras. A huis clos film presents "characters that are isolated from the exterior world” (Bernard 2015, 25). In Ruiz's film, the setting constructs its own private geography which, in turn, enables the Collector to explore further the mystery of the story. We can perceive the different parts of the house as different layers of meaning. The choreography of the filmic spaces creates isolated settings of meaning that are expressed in a fragmented way. Moreover, the fragmented choreography sketches out each scene. Every scene in the film is related to a specific meaning that unfolds in the filmic space. This artificial fragmentation of meaning, through the representation of the paintings, appears through the differentiation and the isolation of every tableau in a variety of spaces. Each fragment corresponds to a tableau vivant attributing a different meaning to the investigation. Every tableau vivant exists on its own and at the same time is linked to every new one that we see as the narration goes on. The tableaux vivants are fragments of an ultimate tableau vivant that does not exist in the physical space, but is performed as a virtual image.

The Collector's and Narrator's investigation is that which connects all of the tableaux vivants. The Collector's movement in space results at the same time in the unraveling of the mystery. Investigation and movement proceed together. The Collector's body links together both physically and virtually the space of the film. As Bernard mentions: "the body links together the fragments in various ways. By its displacement, the body forms a movement and in a relative layout of space in relation to this movement" $(2015,25)$. Along with the displacement of the Collector's body in space, the narration continues, and the more the exploration of the house proceeds, the more we come across different gestures in the spaces of the house.

\section{The Soundscape of the Film}

The spatial organization of the film and the choreography of its scenes are the first attributes of the narration that compose the starting point for the Collector's investigation. It is an artificial set that is being staged for the camera. The Collector has prepared the setting in order to explore along with the camera the spatial configuration of the Ritual. Since the preparation of the set has taken place, the Collector starts a monologue that includes speculations and hypotheses concerning the existence of the paintings. The operation of the voice then is the film's second vital element. In order to explore the filmic space, Ruiz assigns to the voice the 
role of a powerful narrative tool. The Collector's investigation is primarily oral. By exposing his syllogisms in an analytical way, he organizes and then assures the continuity of the narration. In this obscure and occult cinematographic narration, it is the voice that traverses space by marking the potential meaning of each individual scene. The third factor that is related to the other two and plays a key role in the film is the gesture of the bodies. Through their silent gestures, the bodies construct a language that awaits to be deciphered. In this way, each character of the tableaux forms his/her own language that is expressed through the bodily gestures. The three different kinds of languages, the Collector's voice, the Narrator's voice, and the gestures of the tableaux vivants, are interlinked and interact in a play between speech and meaning, between muteness and falsification.

The Collector's bodily image and speech are the primary attributes and characteristics that lead the diegesis of the film. In the beginning of the film, the filmmaker's camera examines, through a tracking shot, a painting. We hear the Narrator's voice and at the same time we follow the camera as it explores the space of the living room. As the camera keeps moving, the Collector enters the shot, and we hear the two voices having a dialogue with each other. The camera continues to follow the Collector as he walks through the living room surrounded by paintings. He presents his thoughts concerning the scandal that the paintings have caused. This is the starting point for the investigation.

The oral investigation along with the movement of his body in the various spaces of the house are the mechanisms of the diegesis. The second voice that is heard throughout the film is that of the Narrator. The Narrator's voice accompanies that of the Collector and it performs a semantic play of meanings. Contrary to the Collector, the Narrator's voice does not have a body. It exists in space and time in an invisible mode. The Narrator interferes throughout the film in an unexpected way, as another play inside Ruiz's narration. The Narrator's voice performs another falsification, similar to those of the simulacra-tableaux. The difference is that this falsehood is both invisible and oral. The function of those two voices, the Collector's and the Narrator's, perform an open play of meanings and interpretations. As Michel Chion argues, the parodying of the voices imitate with their tone the figure of the Masterof-the-House and thus through this play they invite the spectator to participate in the game (Chion 1999, 57).

This game is being produced by the invisibility of the Narrator's voice and by its interaction with that of the Collector. It surrounds the narration with a mystery and at the same time the two voices create a parody of a mystery story. According to Chion the Narrator's voice forms an acousmatic character (Chion 1999, 57). The 
acousmetre exists "neither inside nor outside the image. It is not inside, because the image of the voice's source - the body, the mouth - is not included. Nor is it outside, since it is clearly positioned off-screen in an imaginary 'wing,' like a master of ceremonies or a witness, and it is implicated in the action, constantly about to be part of it" (Chion 1999, 129). The acousmatic character is clearly defined by its ability to appear and disappear in the film's narration, since its existence is not defined by any narrative laws nor does it need to justify its presence. The acousmatic character makes its appearance in an oral way and manifests itself through speech. The Hypothesis of the Stolen Painting presents two different languages, two different expressions that interact and perform a play of languages and bodies, of speech and silence.

\section{Suspension in Time and Space: The Tableaux Vivants}

If the huis clos film has an inherent theatricality due to the enclosed space that is represented in the film, the use of the tableaux vivants doubles the theatricality of the film. The tableau vivant as a practice reached its peak during the 19th century. The adjective vivant refers to the use of bodies in order to construct, literally, a living painting. A related Latin variation of the adjective is the word vivarium, "a noun that refers to a place used for scientific study" (Paz 2017, 1). Both meanings of the word are applicable in the particular study that takes place in the film. The tableaux vivants have been situated in space as actual representations of the paintings that have been confiscated by the police as part of a scandal. The thorough scientific study and the Collector's method of aporetic thinking affirm the aforementioned thesis, which is that the tableau vivant becomes a space of interpretation and of investigation. In his book, Ruiz argued that the recreation of a scene with living bodies is an attempt to recreate the original poses of the original models who sat for the painter. To reconstruct a scene is to be able to capture the tension of the original pose. That is to be able to reincarnate the physical tension of the first models. The reincarnation of the original gestures is the reincarnation of the original tension (Ruiz 2005, 51).

Apart from the physical tension that Ruiz spoke of, tableaux vivants are representations of original and/or supposedly original (as is the case with this film) paintings that aim to concentrate on details such as lighting and shade. With its Neoclassical aesthetic that kind of technique has the quality and the ability to reproduce a painting with living bodies. But its performance is not to exist just as a copy. Its realization is an act of imitation. "This activity of the 19th century salon can be understood as a highly perverse reproductive technique that instead of 
making an original non exchangeable through the multiplication of copies, would render it absolutely singular through its corporeal actualization in 'living material"” - as Michel Goddard points it out $(2013,27)$. The singularity of every tableau vivant lies in its fragmentary representation in time and space. It is a mute representation of a painting that is being performed whilst it empowers the effects of the original. The work of the tableau has at its core a didactic function. It aims at underlying a meaning and a value. This is why the actors remain static. As Steven Jacobs mentions: "tableaux thus represent fixed moments that halt the narrative development of the story and introduce stasis into the movement of the play. During a short period of suspended time, the action is frozen at a point of heightened meaning, a point at which the actor's gestures are especially capable of expressing the full significance and all the implications of the story" $(2011,88)$.

The tableau vivant designates a space as an image in suspension. That kind of image has two designated characteristics: the temporal and the spatial, which form a complex interconnection between time and space. The tableau vivant, which creates a space on its own, a space within the space, reconverts the space into time. This means that space goes through a transformation. Since the characters of the tableau vivant are captured in a specific gesture in time, like freezing time for a specific moment they affect the space that they inhabit by transforming it into time. Anthony Spira explains that Klossowskian subjects "are always captured in flagrante, suspended in time, at the decisive moment, like the cliché as snapshot and also as stereotype" (Spira 2006, 67). The essence of Klossowski's temporality lies in the ephemeral aspect of the tableaux. This occurs because the scenes that are depicted have either a theological-mystical aspect or an erotic one that is presented in a theatrical way. In that way, the gaze of the spectator acquires an interior movement. It transcends itself from time and space in order to be captured by the space that has been opened. Jacques Henric mentions that the strategy that is applied on the spectator's gaze has a double movement since time becomes space, which becomes time again (Henric 1989, 73). It is captured gesture when the character that occurs in time in order to become space in order to become once again time for the spectator.

Arnaud mentions that Klossowski's tableaux vivants are intense and decisive but at the same time are fugitive and elusive (Arnaud, 1990, 163). They can exist only through the complicity of the spectator's gaze, since the decisive moment reveals the tableau vivant to this. In that particular moment of the gaze, it is space that implicates the viewer, making him/her an accomplice. The space of the tableau vivant exists as a host for the fugitive gaze. "The corporeal space, $[\ldots]$ that reproduces 
in its muteness that impenetrable gesture suggests other possible gestures and contradictions" (Klossowski 2001, 131). Time, space and vision become interlinked in the moment of the gaze; time and space possess the gaze in the space that is being opened. The image in suspension is an ephemeral spatio-temporal reality that reveals itself through its becoming simulacrum.

In order to better understand how the tableaux function in the narration, I am presenting them in their chronological order of appearance in the film's narration, since one leads to the other. In the below presented schema, I am following the order of appearance of the thematic scenes [see Fig. 3].

\section{The Series of Tableaux Vivants}

In the beginning of the film, the Collector presents his syllogisms. He appears as if he was giving an interview to someone. We never see another person in a shot nor hear a different voice. The camera is focused on him through a medium close-up. He claims that the painter Tonnere has turned the rules of painting upside down. As the Collector finishes his interview on the imaginary painter, we hear a mysterious music whilst the camera follows the Collector. Suddenly a door opens and the Collector enters it. We are being led to another room. The Collector approaches the window. He uses his binoculars in order to look at the spectacle that takes place in the garden. [Fig. 4.] A high angle shot presents the first tableau vivant. It is the reproduction of a scene from the Greek mythology: Diana and Actaeon. Through a series of medium shots, the filmmaker presents key elements and details of the scene. The mythological scene concerns Acteon, who has been transformed into a deer. This was his punishment for gazing at the goddess while she was having her bath. Suddenly, a mirror held by a boy reflects the sun's rays. [Fig. 5.] "Let us follow their direction" - says the Collector.

Through a tracking shot, the camera follows Diana horizontally as she moves from the garden towards the entrance of the house. The Collector enters the shot form the entrance and he is moving to the right. There we see the sun's ray that is reflected in the window of the basement. Ruiz uses a seventies zooming style in order to focus on the window. The camera zooms in and we see the window. The filmmaker cuts to the interior of the basement where he presents the second tableaux vivant: The Return of the Crusader. [Fig. 6.] The scene depicts a game of chess between two characters. They have been interrupted by the arrival of the crusader. A large shot depicts the four characters of the scene. The Collector continues with his syllogisms. He is focusing on a mirror that has the shape of a crescent. This mirror links the first tableaux with the present one since the ray 
reflected from the garden arrives at this one. The Collector invites the invisible interviewer to follow him. Immediately after that, the camera cuts to another scene in a room. In the centre of the room there is the Hanging Adolescent surrounded by crusaders. [Fig. 7.] As the Collector enters the scene, we see another mirror on the right of the shot. It is a rectangular mirror that reflects a person. The Collector wants us to pay attention to the emplacement of the mirror in the scene. He moves towards the left of the scene and there we see one of the Crusaders being reflected again in a crescent-like mirror. The Collector wants us to pay attention to the light and without any interventions the lighting suddenly changes. Now, the hanging person is being illuminated while the rest of the characters are covered in darkness. Beside that person we see a crusader pointing with his index towards the ceiling. The camera performs a vertical movement towards the ceiling, where we see a mask hanging. The Collector exclaims: "There is the link with the next painting." We hear the Narrator's voice explaining his syllogism and at the same time we see the Collector moving through a dark corridor. Through the staircase, the Collector is moving to the upper floor of the house. We are being led to a large empty room. There, the Collector mentions that there is a hiatus in the series of the paintings. The only thing we see as we leave the room is another mask hanging on the wall. The mystery music reappears in the film's soundtrack and the Collector leaves the room. Now, the Collector attempts to throw light on the mystery of the disappeared painting through a novel. He sits in a chair and starts reading the story whilst at the same time we see the reconstruction of the scenes in tableaux vivants.

After describing the roman-à-clef, the Collector focuses on the thematic clue of the paintings. In a tracking shot we see all of the paintings that the collector possesses and we hear him being led to the conclusion: "We see that the story moves form painting to painting like the hands of a watch." Now, the Collector moves form the examination of each painting to the examination of the gestures of every character. In an extraordinary use of montage, Ruiz presents the gestures of the characters. We see the character of every tableau pointing with his/her finger into the other direction. After this, the filmmaker cuts the scene and presents the next tableau. The Narrator points out that: "We now see that in moving from one painting to the next, the characters are slowly completing the circle each in his own way." The Collector mentions that each one of these gestures leaves an imaginary trace. The scene finishes and the Collector is being led immediately to another room, where we find the altar of Baphomet.

As we can see from the examination of the series of tableaux, movement and stillness are the two predominant factors in the narration. The movement of 
the Collector in the filmic space determines the continuation of the narrative. Additionally, his gaze investigates the possible meaning that the mute and immobile bodies suggest. Also, through the performative function of the voice we are able to construct intellectual hypotheses along the structural path that we follow. The fact that each orchestrated scene functions in relation to another presents a further characteristic of vision in the film: that of the simulacrum. According to Klossowski "the simulacrum as an imitative action is the actualization of something that rests incommunicable in itself or non-representable, that is strictly the fantasy in its obsessional constraint" $(2001,131)$. The function of the body as simulacrum is what creates the diffusion as well as the multiplication of meaning. It is at this point that the narration becomes obscure and creates a confusion for the Collector and the viewers. If we regard each scene separately, we cannot extract a one and unique meaning of its content. But if we think of the virtual circle that is being performed at the end of the narration, then we can conclude that the film's goal is to perform this play through the multiple aspects of vision. The correlation between the incommunicable operation of the simulacra and the performance of the logically structured argumentation of the Collector is what creates the paradox in the film.

In my opinion, Ruiz adopts Klossowski's use of the tableaux vivants as simulacra. Examining more closely the structure of The Hypothesis of the Stolen Painting, we are being led to the conclusion that it is based upon the infinite reproduction of meaning since each simulacrum-tableau vivant leads to another, without a particular aim or goal. Even if on the surface the Collector's syllogisms seem rational or if as an intellectual strategy they produce meaning, Ruiz turns into parody those kinds of syllogisms. It is the conception of a "false infinite" (1990, 227) - as Gilles Deleuze has called it - that we can see in the images constructed as simulacra. Klossowski's images reject the imitative function of traditional painting only to be focused on the work of simulation. Since a false infinite is constructed, the simulacra that imitate the paintings are becoming at the same time the simulacra of simulacra. Ruiz's appropriation of Klossowski's simulacra creates a spiral that we see unfold throughout the film.

\section{Gestures and Language of the Bodies}

The spatial presence of the simulacra is being performed by the tableaux vivants. It is through the gesturality of the living bodies that the Collector and the acousmatic voice aim to derive meanings and interpretations from the paintings. As the investigation proceeds, the Collector focuses all the more on the gestures of the bodies. 
"The same gestures repeated from painting to painting" - as the Collector mentions it in the form of a conclusion. What the investigation of the Collector seeks through the representation of the paintings is the gestures of the bodies; and more precisely the reconstruction of the ritual. The dramaturgy of the gestures gathers together the composition of the ritual. This occurs due to the fact that gestures "have a different value from what they represent" (Arnaud 1990, 70). The bodies of the models are placed in space in a silent mode and through their gestures they convey contradictory meanings. According to Klossowski, motionless gestures which are suspended in space provide "material for a narration that is on its own eternal and inaccessible and without ever having a decisive interpretation” (Klossowski 2001, 137). The gestures of the bodies present a constant ambiguousness. Every image implies another image and in this way the game goes on. The gestures of every figure in the film link all the tableaux vivants together in an interrupted whole that is composed of fragments. The silence of the tableaux vivants and their mute gesturing are the true objects of the Collector's investigation. The film opens up a space where a game between language and gesture, between silence and speech is being played. The Collector performs an oral investigation through language. It is through the signs of language that he tries to reestablish a form of meaning. Gestures on the other hand do not belong to the reign of signs since they are simulacra. In that sense, language tries to capture through signs something that is a non-sign. Simulacra exist on their own, they appear in their fragmentary form, in the form of gestures. They escape the signs of language. The Collector, in presenting the series of tableaux vivants and in analysing them one by one, tries to establish a form of unity. The unification of images in order to produce meaning can only be achieved through the play of language, through speech.

After the examination of the fifth painting, the Collector enters a room where two of the paintings/tableaux vivants are combined together: The Arrival of the Crusader and the Tortures of the Inquisition. The filmic construction connects the Collector's and Narrator's voices with the muteness of the gestures. We can perceive this in the following lines:

Narrator: A series of paintings linked by minor details, sometimes skillfully inserted extraneously to the theme: the ray of the light in the mirror, the second mirror in the shape of a crescent. And now...

Collector: I would like to draw your attention to the extreme care with which the painter has placed the mirrors. So that it is really impossible to err in arranging the tableaux vivants.

Narrator: Is such care likely? 
Collector: What else is the painter's purpose but to draw our attention to what is reflected in the mirror when the tableau is arranged? Look, it is he one sees reflected in the mirror. But now let us consider the lighting effects. The chiaroscuro obviously is arbitrary. Why should certain figures, perhaps not the most important, be privileged and others remain a shadow? But setting aside the lighting, let us concentrate on the figures.

The Collector switches on the lights and continues: "All is clear. Let us reverse the lighting. Let what was played in shadow emerge into the light and what was clearly visible return to the darkness." The Collector now looks at the gesture of the Crusader. His finger points toward the ceiling. The Collector looks up and sees the mask. He exclaims: "the mask" [Fig. 8]. The Collector and the Narrator now have the clue in order to proceed with the investigation. The narrator mentions that the mask is an element of the stolen painting and concludes, in a contradictory manner, that this painting does not exist.

As we can observe from the above, the Collector presents one of the possible interpretations of the bodily gestures. In this obscure narration that constantly escapes one possible interpretation, language and silence coexist. Ruiz constructs a play between visibility and invisibility: the visibility of the bodies and the invisibility of the inaccessible that lies in the simulacra-images. This association of the gaze with speech acquires the quality of the essential relation, which consists in the complicity of sight and speech (Deleuze 1990, 284). This complicity must be understood here as a disjunction between body and language. First and foremost it is the language of the bodies that guides the syllogisms that are heard aloud in the film.

The bodies perform the event for the viewer. Each network of gestures, every tableau vivant becomes an event. The gesture is that which is proposed as an event, which surpasses language. And that is the function of the simulacra: they encompass the phantasm that language seeks to define. "The body is language because it is essentially 'flexion'. In reflection, the corporeal flexion seems to be divided, split in two, opposed to itself and reflected in itself, it appears finally for itself, liberated from everything that ordinarily conceals it." (Deleuze 1990, 286.) The Collector forms his syllogisms upon the reflection on the bodies. His language then is the reflected intentionality of the gestures. This intentionality that is clearly depicted in the gesture is the actual event. "The event occurring in a state of affairs and the sense inhering in the proposition are the same entity. Consequently, to the extent that the incorporeal event is constituted and constitutes the surface, it raises to this surface the terms of its double reference: the bodies to which it refers as a noematic attribute, and the propositions to which it refers as an expressible entity. 
It organizes these terms as two series which it separates, since it is by and in this separation that it distinguishes itself from the bodies from which it ensues and from the propositions it renders possible.” (Deleuze 1990, 182.)

\section{The Virtual Image}

After exposing the series of tableaux in the space of the house, the Collector seems puzzled and resorts to a small book which is a roman-à-clef. This literary genre, which means a novel with a symbolic key to the story reflects real characters and real events in the form of a fictitious story. The Collector starts to read the novel. As he narrates, we see at the same time the reproduction of the story in the form of tableaux vivants. That technique is the ultimate narration that combines at the same time language and gestures. At first glance, the story is a typical bourgeois story that concerns the marriage of a young girl and her fiancé. Things start to become complicated when one of the guests starts to have homoerotic tendencies towards the fiancé. The more the narration proceeds, the more we come closer to the truth. The Collector finishes the story with the following incident: "That very night, the boy L. is carried off by $\mathrm{H}$. aided by members of the sect and taken to their mansion in the rue de la Pompe. Promptly alerted by the Marquise, the police intervene and interrupt a strange ceremony involving young L. as both priest and sacrifice. The protagonists all find themselves in prison and are released on payment of a substantial bail. Young L. is found hanged in his cell and the talk is either of suicide or a crime." The Collector finishes his narration of the story with the following rhetoric question. "Can we accept that what lies behind these paintings is merely a novel?" "We can say that the protagonists simply portrayed the novel's theme as if it were a ceremony" - he adds.

As we approach to the final phase of the film, the Collector informs us that the stolen painting does not exist. The Collector traced the occult theme that lies hidden in all of the paintings and Ruiz's camera movement has performed a virtual circle that led from one painting to the next inside the space of the house. The paintings are compared to circles that all together lead to the sphere: Baphomet. In fact, the Collector has recreated the ceremony for the film. The paintings are the ceremony. Each gesture of the bodies in the tableaux vivants is part of the ceremony.

We are now being led to the conclusion that the ceremony is the concept of the eternal return (Circulus Vitiosus Deus according to Klossowski). The virtual circles that have been produced in the film are singularities whose actualized intentionality forms the idea of the Whole as it is (re)presented in the film. At the end what we 
see is a synthesis of the different singular gestures of all the tableaux vivants that are represented in the film. [Fig. 9.] We see a fusion of all the characters together. A tracking shot examines now, slowly, the figures. The protagonists of the different paintings are being unified: Diana and the Crusaders, the characters from the roman-à-clef all become one by their placement in the same space. The fragmentssingularities, which are the circles, are now an actual visualization of the sphere.

The gesturality of the bodies actualizes in every tableau vivant an event, since the series of the events form the Circle. This is what the end of the film reveals: that the whole narration unfolded a series of events, in a strategic manner, in order to complete a virtual circle. We have come across a series of tableaux vivants that at the beginning seemed as simple reproductions of paintings, only to be revealed later on that they are actual events in a perverse ceremony that was taking place in the filmic space. In other words, the filmmaker has made the viewer an accomplice of this ceremony.

\section{Conclusion}

The filmmaker disclosed in his mise-en-scène the mystery that proves not to be a mystery but rather a parody of a mystery story. He purposely misled the viewers by making them participate in the ritual as they followed meticulously the narration. The forming of the complete circle, which leads to the appearance of Baphomet, is the goal of the narration of the film. We could claim that the whole narration is a conspiracy of signs that become simulacra in order to interact with each other in a game of language and gestures.

In my article, I have attempted to demonstrate how cinema can operate as a "thought experiment" (Elsaesser, 2018). I have based my approach on the conception that the cinematic medium can perform an intellectual experimentation through the creation of a visual system. Dismantling the theme of the film, I have sketched out the references to the philosophical and pictorial work of Pierre Klossowski. Additionally, I have underlined how Klossowski's personal mythology has been incorporated into the theme of the film. I aimed at demonstrating how several philosophical concepts (such as the simulacrum, the eternal return) have been expressed in cinematic terms.

The Hypothesis of Stolen Painting is one of cinema's attempts to form a complete world on its own, transcending the ephemeral (re)construction of the world. At the same time, there is a paradoxical relation between the visual and the virtual that takes place through the use of the tableaux vivants. Ultimately, the junction 
between the philosophical and pictorial work of Klossowski and the cinematic language of Ruiz points to the relation between the representable and the noncommunicable. This filmic construction is able to perform its synthetic function through the interplay between the visual and the virtual.

\section{References}

Arnaud, Alain. 1990. Pierre Klossowski. Paris: Seuil.

Bernard, Marion. 2015. Continuité de l'espace unique: la scripte face au huis clos [Continuity of the Unique Space: the Script Confronting the Huis Clos]. Paris: La F.E.M.I.S.

Chion, Michel. 1999. The Voice in Cinema. New York: Columbia University Press.

Deleuze, Gilles. 1990. The Logic of Sense. London: The Athlone Press.

Goddard, Michael. 2013. Impossible Cartographies: Approaching Raúl Ruiz's Cinema. Em Questão. Revista da Faculdade de Biblioteconomia e Comunicação da UFRGS, vol. 19. no. 1: 21-41.

Elsaesser, Thomas. 2018. European Cinema and Continental Philosophy. Film as Thought Experiment. London: Bloomsbury Academic.

Henric, Jacques. 1989. Pierre Klossowski. Paris: Adam Biro.

Jacobs, Steven. 2011. Framing Pictures, Film and the Visual Arts. Edinburgh: Edinburgh University Press.

Klossowski, Pierre. 1997. Nietzsche and the Vicious Circle. London: The Athlone Press.

Klossowski, Pierre. 2001. Tableaux Vivants, Essais critiques 1936-1983 [Tableaux Vivants: Critical Essays 1936-1983]. Paris: Gallimard.

Mahon, Alyce. 2006. The Sadean Imagination: Pierre Klossowski and the 'Vicious Circle.' In Pierre Klossowski, eds. Anthony Spira and Sarah Wilson, 30-41. Ostfildern: Hatje Cantz.

Paz, Danielle. 2017. 'Tableau Vivant' in the University of Chicago. Theories of Media Glossary. https://lucian.uchicago.edu/blogs/mediatheory/keywords/tableauvivant. Last accessed 30. 08. 2018.

Ruiz, Raúl. 2005. Poetics of Cinema. Paris: Dis Voir.

Spira, Anthony. 2006. A Pantomime of Spirits. In Pierre Klossowski, eds. Anthony Spira and Sarah Wilson, 60-77. Ostfildern: Hatje Cantz. 


\section{List of Figures}

Figure 1. Spaces of the House.

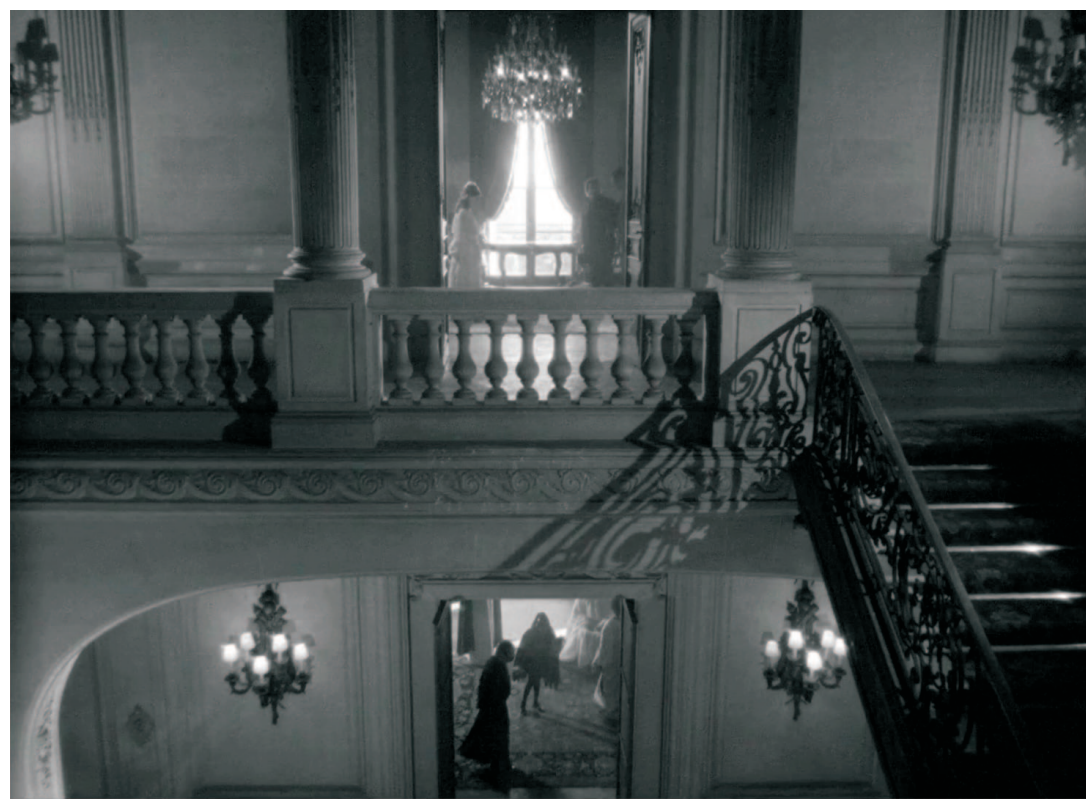

Figure 2. The Collector traversing one of the dark corridors of the house.

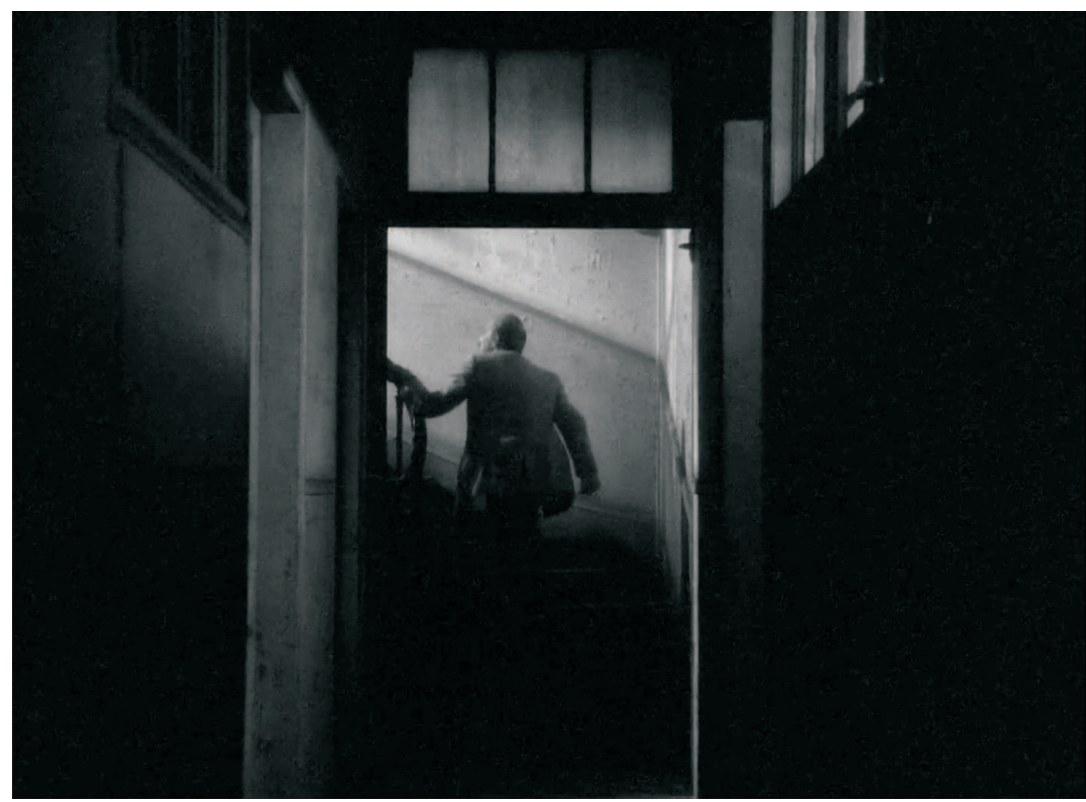




\section{Figure 3.}
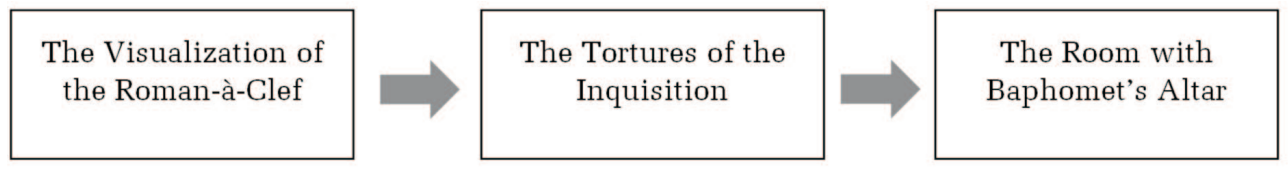

The Empty Room with the Mask/ The Missing Painting
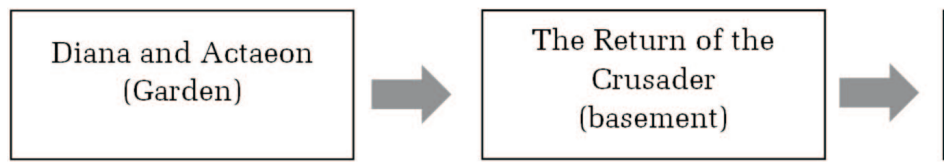

The room with the Hanging Adolescent

Figure 4. The Collector observes the first tableau vivant from the window.

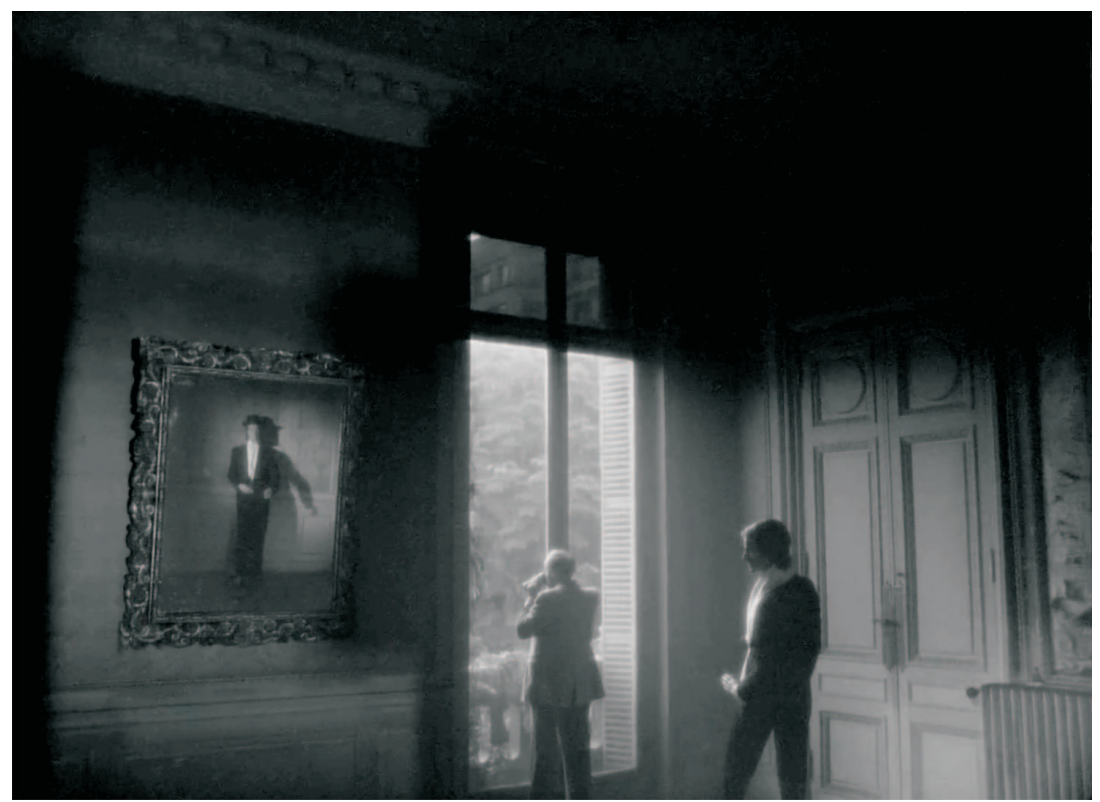


Figure 5. Diana and Actaeon in the garden. We can see the ray of light reflected towards the basement.

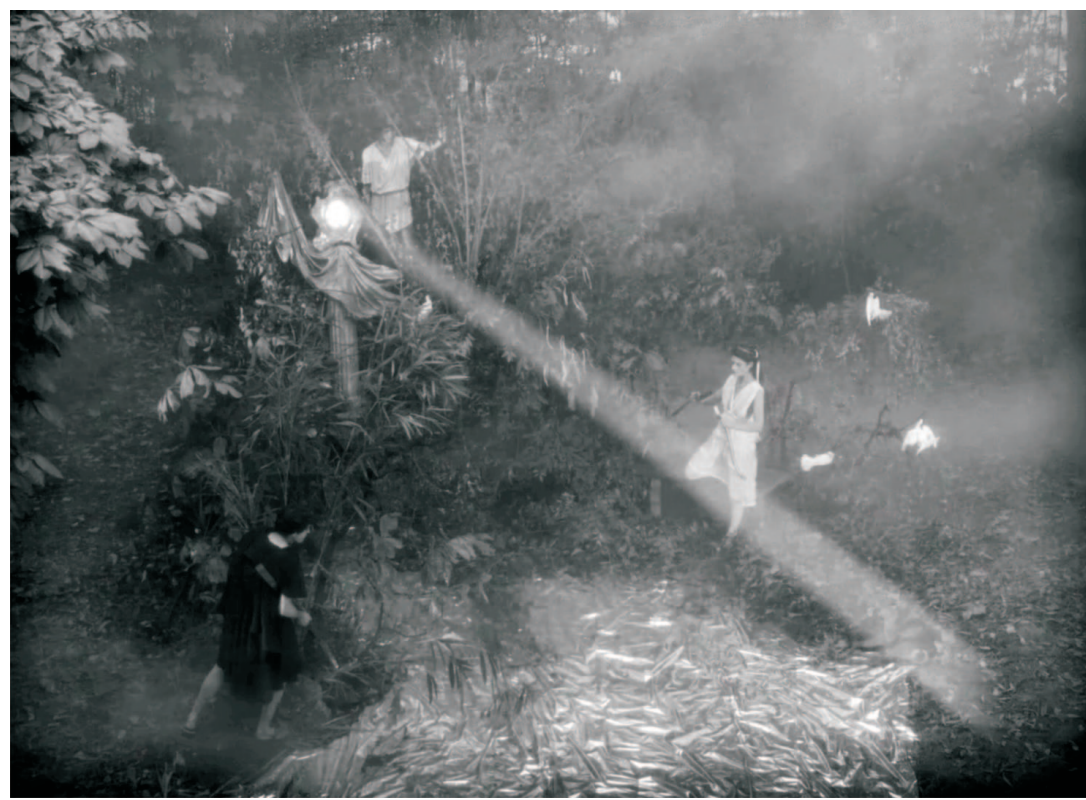

Figure 6. The Return of the Crusader. The second tableau vivant in the basement.

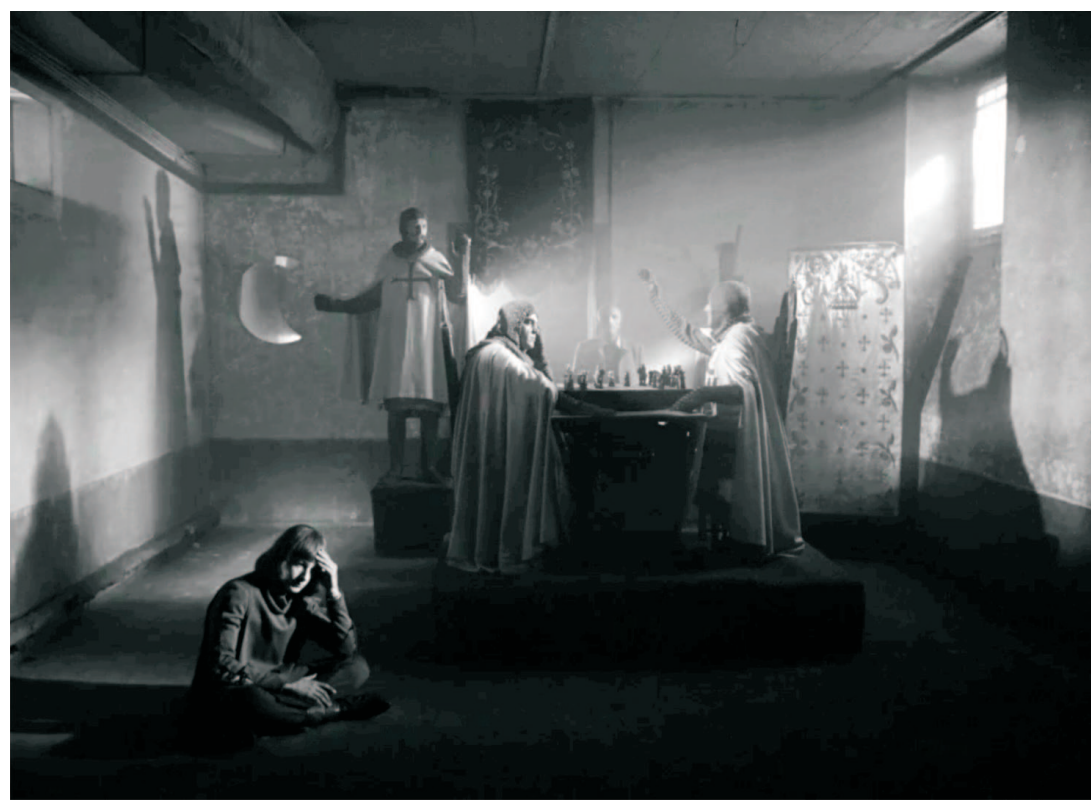


Figure 7. The Hanging Adolescent. The Collector's reflection is visible in the mirror on the right.

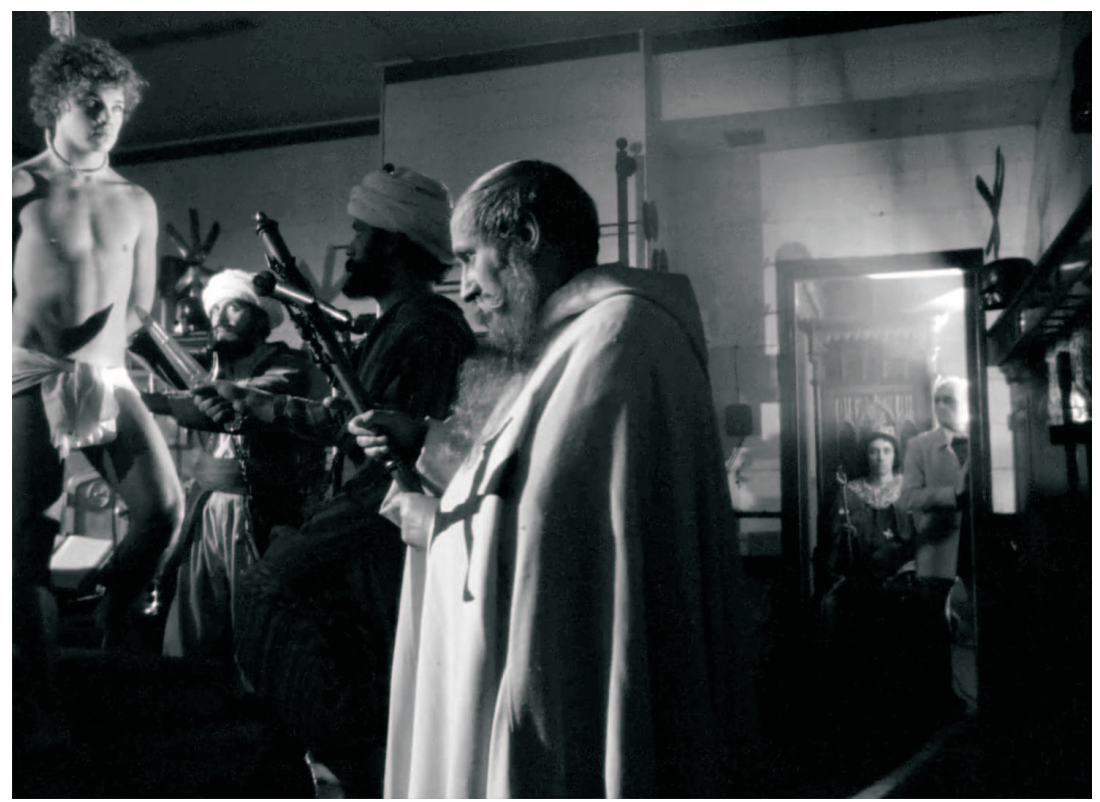

Figure 8. Revealing the mask.

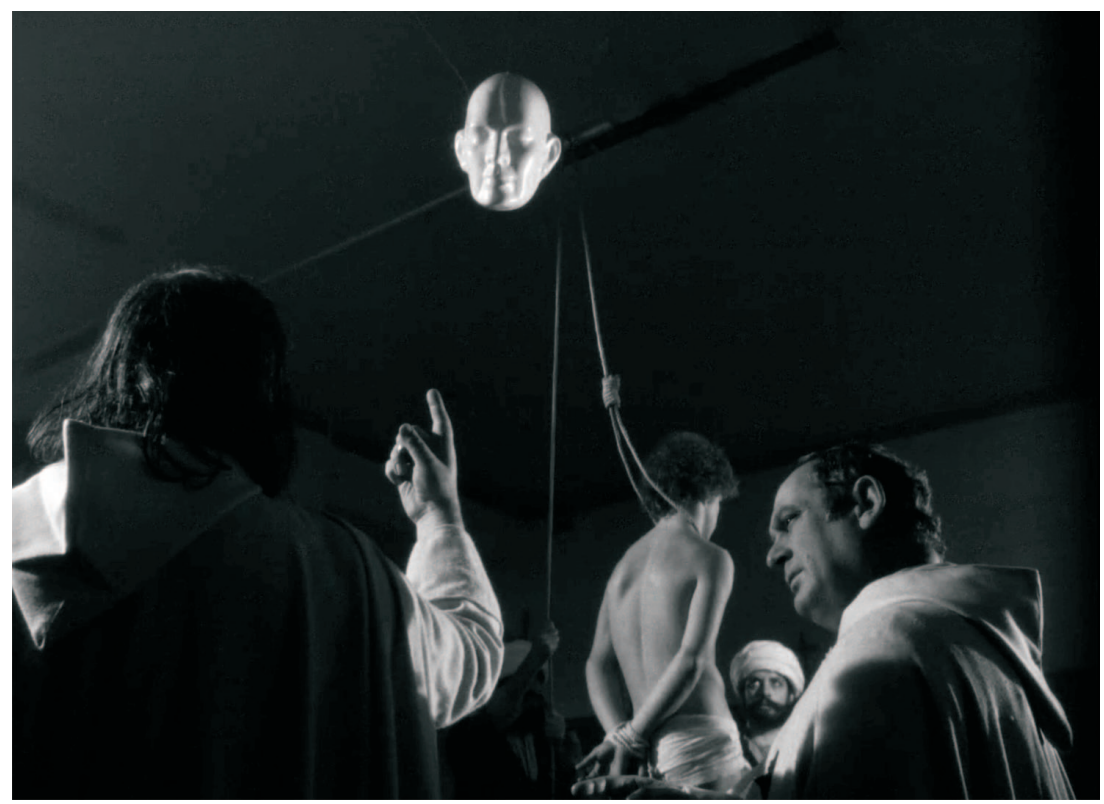


Figure 9. A synthesis of all the tableaux and the different gestures unified in one space.

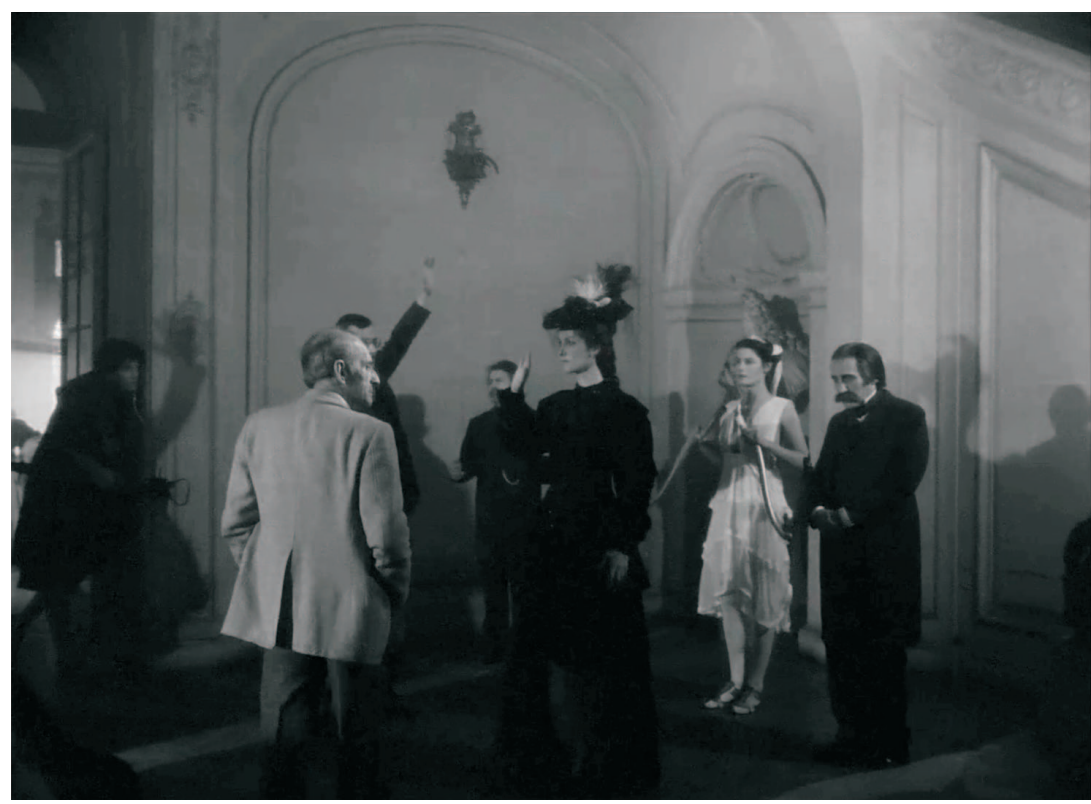

